\title{
Project-Based Learning as an Important Element of Training Students Majoring in Environmental Engineering
}

\author{
Natalia Semenova ${ }^{1, *}$ \\ ${ }^{1}$ Saint Petersburg State University of Architecture and Civil Engineering, 190005, Saint Petersburg, \\ Russia
}

\begin{abstract}
The paper addresses the training of specialists in civil engineering, having skills in project activities and advanced design techniques. Including technologies for the design of facilities, taking into account environmental norms and rules of nature management. Teamwork skills are one of the important competencies of a modern specialist. The paper describes ways to implement students' teamwork in the training process at universities. It is shown how collective training techniques are introduced to the training process of engineering students. The author notes the importance of further development of project-based learning for the training of specialists in civil engineering, architecture and other engineering fields. It is also noted that the accomplishment of assignments - and not only individually but also in micro-groups — often adds a competitive aspect to the process, helps reveal leadership skills, and makes it possible for students to fulfill themselves at their best and demonstrate their talents. Collective assignments always require thinking outside the box, looking for unconventional solutions, and make students have an open mind. The paper also addresses matters of developing the graphic culture in students during their training and highlights the importance of the graphic culture in the training of highly qualified specialists.
\end{abstract}

\section{Introduction}

The current pace of technological development requires the introduction of new approaches to the students' training process. In particular, teaching teamwork skills, which is implemented in the training process as a part of project-based activities, requires new approaches [1-6].

Many authors define a class project as special and motivated independent work of students. Class projects are usually intended to solve a specific and significant practical or theoretical problem, presented in the form of a finished product that can be seen, comprehended and applied in practical work. The results of such training can be divided into two main groups: acquisition, consolidation and development of knowledge and skills (competencies) that have practical significance and are required for the preferred

\footnotetext{
*Corresponding author: sna.spbgasu@gmail.com
} 
professional activities; personal competencies and self-organization skills. A class project involving students is characterized by clearly set tasks, accomplishment criteria, and limited deadlines. Project-based activities represent one of the types of learning activities that students carry out when mastering their educational programs [7].

In order to become the most sought-after specialists, in the course of the learning process, students should gain experience in solving real-world problems concerning their future profession; experience in actual research and design activities carried out now rather than in future; experience in teamwork and deadline management; experience in being responsible for the results [7].

The purpose of the study is to identify the specifics of implementing project-based learning for students majoring in architecture and civil engineering.

\section{Materials and methods}

Prior to starting projects, students enrolled in engineering programs should master a lot of minor subjects that help them master the tools required for more complex tasks. This is due to the fact that project-based subjects, as well as elective and scientific projects that imply teamwork, are intended to develop competencies that account for the collaborative effort, interaction, and relationships between the theoretical knowledge acquired earlier and the practical experience. To perform such projects, a student shall have a command of a basic set of general professional competencies, applying those in practice and not starting mastering them "from square one" at the start of a project.

To participate in a project, civil engineering students shall: have such skills as the skill to interpret builder's blueprints and mechanical engineering drawings, make calculations and drawings; know the rules of reading design and technical documentation, rules of making technical and design drawings, sketches and diagrams. It is worth mentioning the importance of successful mastering of these competencies by students who need to work with drawings in their subsequent professional activities.

As a result, students acquire sound knowledge and skills that determine training in graphics necessary for their subsequent project work. They develop spatial and logical thinking, the ability to analyze and synthesize graphic models implemented as drawings of specific 3D objects.

I. Yu. Amirdzhanova and V. G. Vitkalov [8] make a conclusion that training in graphics is a necessary component of higher education. In combination with computer technologies, this ensures that students acquire competencies not only in engineering graphics but also in general engineering and special disciplines, all the way to practical use in production activities, and, therefore, improves their graphic culture.

For many years, modern architectural and civil engineering designs have been made with the use of computers and software. The next stage in the student's preparation for project-based activities is to get acquainted with specialized information technologies. Thus, knowing the main rules of working with drawings, understanding the principles of their development, and having acquired the necessary graphic culture [8], a student can continue with the use of automated design systems (CAD).

The paper [9] describes the process of training students in descriptive geometry and engineering graphics with the use of modern information technologies and CAD systems. The paper presents a method of giving classes in an integrated course, during which students simultaneously learn both traditional methods of making drawings in accordance with state standards (GOSTs) of the unified system of design documentation (ESKD) and tools and methods of 3D modeling as well as execution of design documentation using a CAD system. 
The paper [10] presents a general innovative model of training students in geometry and graphics, the central element of which is the use of a wide range of modern information technologies. The implementation of this model and consideration of features of technologies applied have made it possible to achieve significant results and, inter alia, create an educational environment with conditions simulating actual on-the-job conditions in design engineering.

The skill of working with a CAD system became one of the main competencies of a graduate of a civil engineering university a long time ago [9-13]. However, in recent years, a more complex approach to solving construction problems has appeared, which is building information modeling (BIM) [14-16].

This approach requires teamwork skills even more. In fact, it is based on teamwork. The concept of BIM is that information on all elements of a building is contained in a single computer model, with the elements not only drawn but also supplemented with information on their characteristics. This approach is also distinctive in the fact that project work can be done not sequentially but in parallel, i.e. simultaneously by all participants. Thus, no time is wasted and all errors and collisions are identified immediately. As a result, project participants shall be constantly in contact with each other; they shall communicate, agree upon their actions, and depend on each other in many aspects. Thus, studying BIM technologies directly simulates the process of performing actual tasks in a construction or architectural organization.

The inevitability of comprehensive introduction and development of these technologies is predetermined not only by the advantages of optimized teamwork. As a rule, modern software packages that make it possible to conduct building information modeling have a large library of standard elements, which relieves a designer from the need to draw all elements manually. A building is assembled as a "construction set" instead.

In fact, when BIM is used, centralization and systematization of data storage are carried out and all processes become more "transparent" and effective. The experience of many countries shows that BIM offers a significant development for the construction industry, and a modern specialist shall master this technology.

In order to be trained in working with specialized BIM software, students, first of all, shall make the way described earlier, from drawing lines and projections with a pencil to working with modern CAD systems. This is the only approach that will make it possible for them to comfortably dive into a large information model, with many different specialists participating in its development, and comprehend this model, while having the graphic culture $[17,18]$ and teamwork skills.

It is very important for future work in the construction industry since the process of erecting new buildings, from the development of an architectural concept to the commissioning of the facility, is a concerted effort of many specialists. In this industry, specialists have always worked together, but today, the modern pace of life and the financial aspect of construction activities require fast work and compliance with all scheduled deadlines.

Having found a job, a graduate right away makes it into a complex mechanism of a design organization. General ideas on the implementation of a project are developed by all employees together. And any young professional engineer must learn how to cultivate relations and productive communication with the associates in order to work successfully.

Thus, when a young specialist, having not only theoretical knowledge and practical skills but teamwork skills as well, understanding and knowing the BIM concept, enters a working environment, such skills will be a great advantage to him or her and will provide the necessary psychological background.

While it is difficult to prepare a student for future working relations, it is also possible. Moreover, it can be done during freshman classes. 
How is it possible to help a student acquire teamwork skills prior to studying projectbased disciplines and electives? For example, the accomplishment of assignments — and not only individually but also in micro-groups - often adds a competitive aspect to the process and makes it possible for students to fulfill themselves at their best and demonstrate their talents. Such collective assignments always require thinking outside the box, looking for unconventional solutions, and make students have an open mind.

There are two main types of collective assignments:

1. All members of the team are engaged in one project, one task, jointly looking for ways to solve it by discussing it and suggesting different options. Such an approach also makes it possible to find the most reasonable solution to the task.

2. All team members participating in a common project perform their own tasks and are responsible for that task only. However, in this case, it is necessary to ensure that the work of each student correlates with the work of other members in terms of all parameters.

Both options imply a creative approach since all participants, one way or another, look towards implementing their own idea. Only large, diverse and interesting assignments and projects that require a lot of thinking and, of course, the interest of students are needed. It is necessary to show every student that there are many ways of implementing ideas in any matter.

Another option of implementing students' teamwork is to prepare joint reports and speeches at seminars and conferences. In particular, such teamwork can include a search for materials for a common topic, a speech with a presentation that has been developed by students jointly, a speech of each student presenting their own research, as well as the collective presentation of their ideas and work. All of that is possible when people are compatible psychologically and can come to an agreement and find a middle ground. In this case, each person will bring something individual and something new to the project, and then the process will develop.

When delivering speeches at conferences, team members inform the audience of the information they have gathered and everything they think necessary, useful and scientifically-based. Joint reports and assembled individual results of a large research project also demonstrate a more in-depth study of a certain topic. Teamwork gives a student a sense of responsibility and provides a serious approach to the task. The risk of failing other participants of the project and not fulfilling the tasks within the deadline allows them to develop necessary business traits.

The presentation of implemented projects with a subsequent discussion, where specialists from relevant companies, i.e. potential employers who have experience in the area, can be invited to, is a good practice for students to develop skills to critically assess their professional strengths and weaknesses. During such presentations, students answer questions and they can express their opinions both on their own projects and projects of others, distinguish the best projects and explain their choice, give advice to each other (what can be improved and what requires further work).

Senior students can find and choose their own topics for their projects, take on realworld assignments; they show a keen interest in practical and significant issues. By carrying out projects similar to real ones, students become more aware of the significance of their future profession.

In such a way, some students can demonstrate their leadership skills, and that is an important result of the project work during studies. To ensure successful and efficient work, each team needs a leader (in the context of training future specialists in construction, those are project captains and project managers). The work in a team project will allow them not only to develop their skills even more, but also to organize and push other participants, and, therefore, the whole project. A leader is necessary for the efficient and successful work of the team because a leader takes on many important duties: sets the team's values, ensures 
compliance with the rules, creates an optimistic attitude and leads by example. Besides, a leader interacts with the management in a centralized way (in the context of class projects

- with a teacher) and coordinates the activities of all process participants.

In addition to the fact that the skills acquired are needed in their future profession, valuable experience in project-based activities gained by freshman students can serve the basis for further research work or a graduation thesis.

Of course, not all students are able to master even the basic training program, and not all study groups have creative and talented students. Moreover, creative teamwork and joint scientific efforts require a lot more energy and time. Nevertheless, the development of teamwork skills and students' participation in research and innovative activities at universities is a significant advantage in training future employees for construction organizations.

\section{Conclusion}

The continuous development of modern design technologies requires the timely update of educational programs and the improvement of learning technologies. When assessing the capabilities of BIM technologies being developed and implemented, we can conclude that they are the future of civil engineering and architecture, which makes teamwork especially important. In the learning process, this can be achieved by actively introducing projectbased learning techniques; both teachers and employers actively support their introduction. However, during the transition to advanced information technologies, we should not forget the graphic culture and the understanding of the principles used by computers in design.

\section{References}

1. A. M. Ruiz-Ortega, J. J. Gallardo-Rodríguez, E. Navarro-López, M. del C. CerónGarcía, Education for Chemical Engineers, 29(1), 1-8 (2019) doi: 10.1016/j.ece.2019.05.004

2. S. Cicmil, H. Gaggiotti, International Journal of Project Management, 36, 208-218 (2018) doi: 10.1016/j.ijproman.2017.07.005

3. L. I. Eremina, Modern problems of science and education, (2), 292 (2013)

4. E. Popova. Informative Bulletin of Association History and Computer, (42), 204-206 (2014)

5. E. A. Aleshugina, O. I. Vaganova, A. V. Trutanova, Modern Science Success, 2(11), 122-124 (2016)

6. N. Semenova, MATEC Web Conf., 193, 03038 (2018) doi: 10.1051/matecconf/201819303038

7. Project training. University Implementation Practices. Ed. L. A. Evstratova, N. V. Isaeva, O. V. Leshukov. Moscow, 154 (2018) DOI: 10.17323/978-5-7598-1916-5

8. I. Yu. Amirdzhanova, V. G. Vitkalov, Vector of sciences. Togliatti State University, (2-2), 26-31 (2015)

9. A. V. Blinov, Yu. V. Bozhko, V. M. Korobov, V. V. Scherbakov, Modern problems of science and education, (2), 188 (2013)

10. I. D. Stolbova, E. P. Aleksandrova, K. G. Nosov. Open Education, 21(1), 59-67 (2017) doi: 10.21686/1818-4243-2017-1-59-67

11. C. Alves, G. Putnik. Procedia CIRP, 84, 209-214 (2019) doi: 10.1016/j.procir.2019.07.002

12. Ö. Gül, Procedia - Social and Behavioral Sciences, 174, 1758-1763 (2015) doi: 10.1016/j.sbspro.2015.01.834 
13. D. A. Field, Computer-Aided Design, 36, 1431-1437 (2004) doi: 10.1016/j.cad.2003.10.007

14. A. S. Lushnikov, Bulletin of Civil Engineers, 6(53), 252-256 (2015)

15. J. Fridrich, K. Kubečka, Procedia - Social and Behavioral Sciences, 141, 763-767 (2014) doi: 10.1016/j.sbspro.2014.05.134

16. A. Abbas, Z. U. Din, R. Farooqui, Procedia Engineering, 145, 151-157 (2016) doi: 10.1016/j.proeng.2016.04.034

17. N. A. Semenova, BIM in Construction \& Architecture: Proceedings of the All-Russian scientific-practical conference, 227-230 (2018)

18. A. Chegu Badrinath, Y. Chang, S. Hsieh, Visualization in Engineering, 4(9), 1-17 (2016) doi: 10.1186/s40327-016-0038-6 